\title{
Fístula ventrículo-colónica como complicación tardía de catéter ventrículo peritoneal
}

\author{
Ventriculo-colonic fistula as late complication of peritoneal ventricular catheter
}

Nelson Muñoz P. ${ }^{1}$, Fatme Díaz G. ${ }^{2}$, Roberto Durán F. ${ }^{1}$ y Juan Mansilla E. ${ }^{1}$

Mujer 29 años, usuaria de derivación ventrículo peritoneal (DVP) desde hace 9 años por antecedente de hemorragia subaracnoidea e hidrocefalia, consulta por dolor abdominal intenso, vómitos explosivos, cefalea y fiebre; examen físico: destacan signos meníngeos, sin signos de irritación peritoneal. TC abdomen y pelvis (Figuras 1, 2 y 3): DVP fistulizada a colon descendente, sin colecciones intraabdominales. Neurocirugía desconecta DVP y realiza drenaje ventricular externo; mediante colonoscopia se retira catéter con asa de diatermia. (Figura 4). Completa 14 días de tratamiento antibiótico con buena evolución instalándose nueva derivación ventrículo peritoneal sin incidentes.

Las derivaciones ventrículo-peritoneales (DVP) son el tratamiento estándar de la hidrocefalia, sin embargo, están asociadas a complicaciones severas, que incluyen obstrucción, infección (peritonitis, ventriculitis y meningitis), migración y perforación. La perforación al tracto gastrointestinal como complicación tardía de DVP se presenta en el 0,1-0,7\%;

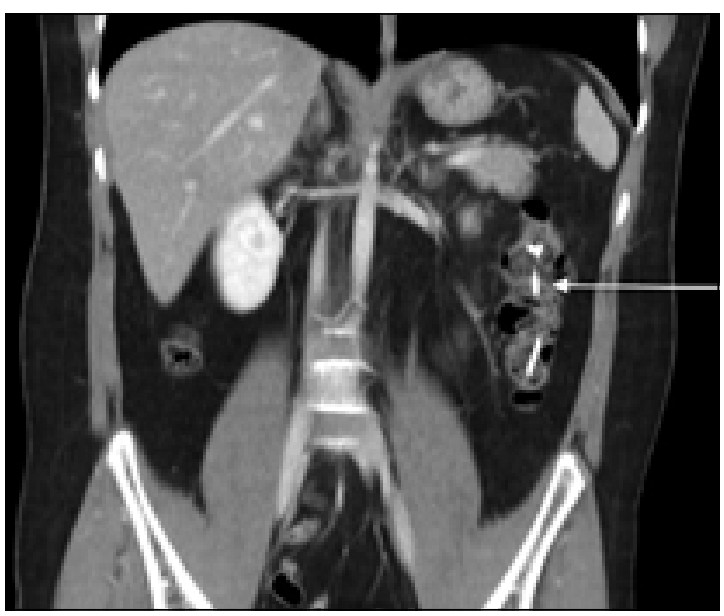

Figura 1. TC AP, corte coronal. Secuencia de ingreso de catéter de válvula ventrículo-peritoneal fistulizada a colon descendente.

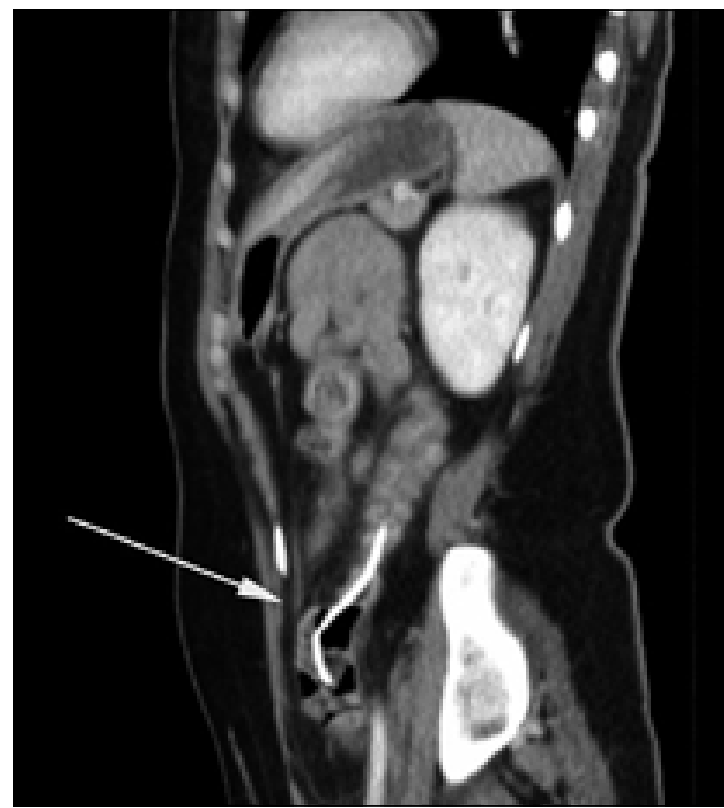

Departamento de

Cirugía, Traumatología y Anestesiología, Hospital Dr. Hernán Henríquez Aravena. Temuco, Chile.

2Facultad de Medicina, Universidad de La Frontera. Temuco, Chile.

Recibido el 20 de febrero de 2019 y aceptado para publicación el 23 de abril de 2019.

Correspondencia a: Dr. Juan Andrés Mansilla E. jamansilla@gmail.com
Figura 2. $T C A P$, corte sagital. Catéter $D V P$ en fistulizado en colon descendente.

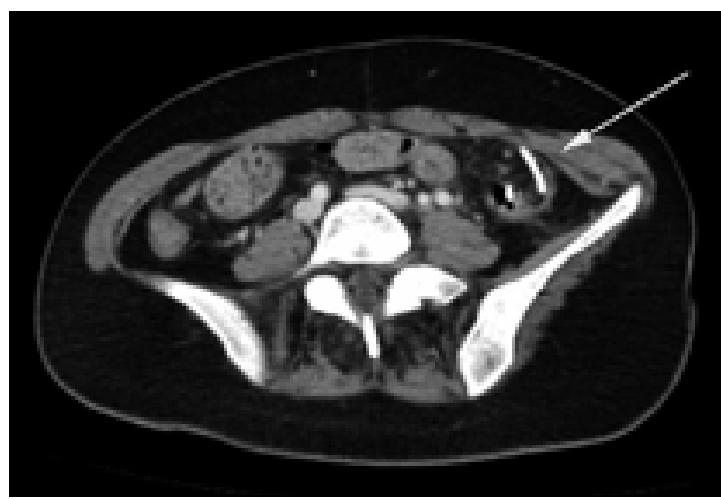

Figura 3. TC AP, corte axial. Catéter DVP en colon descendente. 


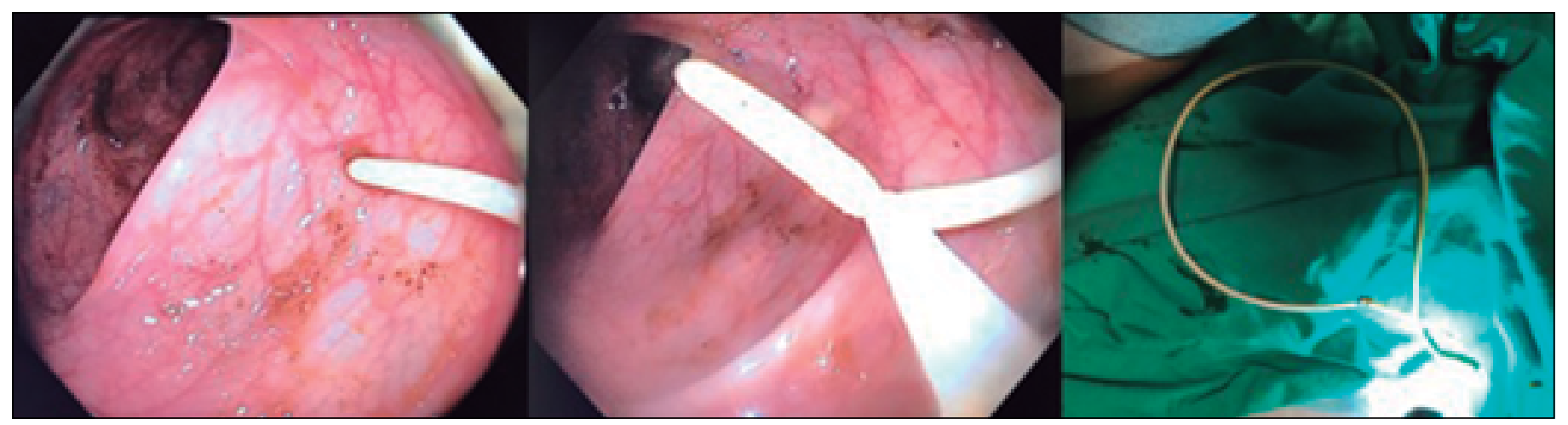

Figura 4. a) Derivación ventrículo peritoneal a nivel colon sigmoide; b) Extracción de derivación mediante asa de diatermia; c) Catéter de derivación retirado mediante colonoscopia.

clínicamente menos de un $25 \%$ presenta signos de irritación peritoneal ${ }^{1}$. El tratamiento consiste en desfuncionalización proximal DVP, antibioticoterapia y retiro del extremo perforante ${ }^{2}$. El abordaje mínimamente invasivo es la elección en estos pacientes ${ }^{3}$.

\section{Responsabilidades éticas}

Protección de personas y animales: Los autores declaran que para esta investigación no se han realizado experimentos en seres humanos ni en animales.
Confidencialidad de los datos: Los autores declaran que han seguido los protocolos de su centro de trabajo sobre la publicación de datos de pacientes.

Derecho a la privacidad y consentimiento informado: Los autores han obtenido el consentimiento informado de los pacientes y/o sujetos referidos en el artículo.

Financiamiento: El presente trabajo no posee fuente de financiación.

Conflictos de interés: no hay.

\section{Bibliografía}

1. Alves A, Mendes S, Lopes S, Monteiro A, Perdigoto D, Amaro P, et al. Endoscopic Management of Colonic Perforation due to Ventriculoperitoneal Shunt: Case Report and Literature Review. GE
Port J Gastroenterol. 2017;24:232-6. doi: 10.1159/000454987.

2. Pikoulis E, Psallidas N, Daskalakis P, Kouzelis K, Leppäniemi A, Tsatsoulis P. et al. A rare complication of a ventriculoperitoneal shunt resolved by colonoscopy. Endoscopy 2003;35:463.
3. Rinker EK, Osborn DA, Williams TR, Spizarny DL. Asymptomatic bowel perforation by abandoned ventriculoperitoneal shunt. J Radiol Case Rep. 2013;7:1-8. Published 2013 Sep 1. doi:10.3941/jrcr. v7i9.1243. 